\title{
Recent Insights for Achieving Mixed Halide Perovskites Without Halide Segregation
}

\author{
Andrés. F. Gualdrón-Reyes, ${ }^{1,2,3}$ Seog Joon Yoon, ${ }^{1 *}$ and Iván Mora-Seró ${ }^{1 *}$
}

${ }^{1}$ Institute of Advanced Materials (INAM), University Jaume I, Avenida de Vicent Sos Baynat, s/n, 12006 Castelló de la Plana, Castellón, Spain

${ }^{2}$ Centro de Investigaciones en Catálisis (CICAT)

${ }^{3}$ Centro de Investigación Científica y Tecnológica en Materiales y Nanociencias (CMN), Universidad Industrial de Santander, Piedecuesta, Santander, Colombia. C.P. 681011.

*Corresponding author: yoon@uji.es, sero@uji.es

TOC

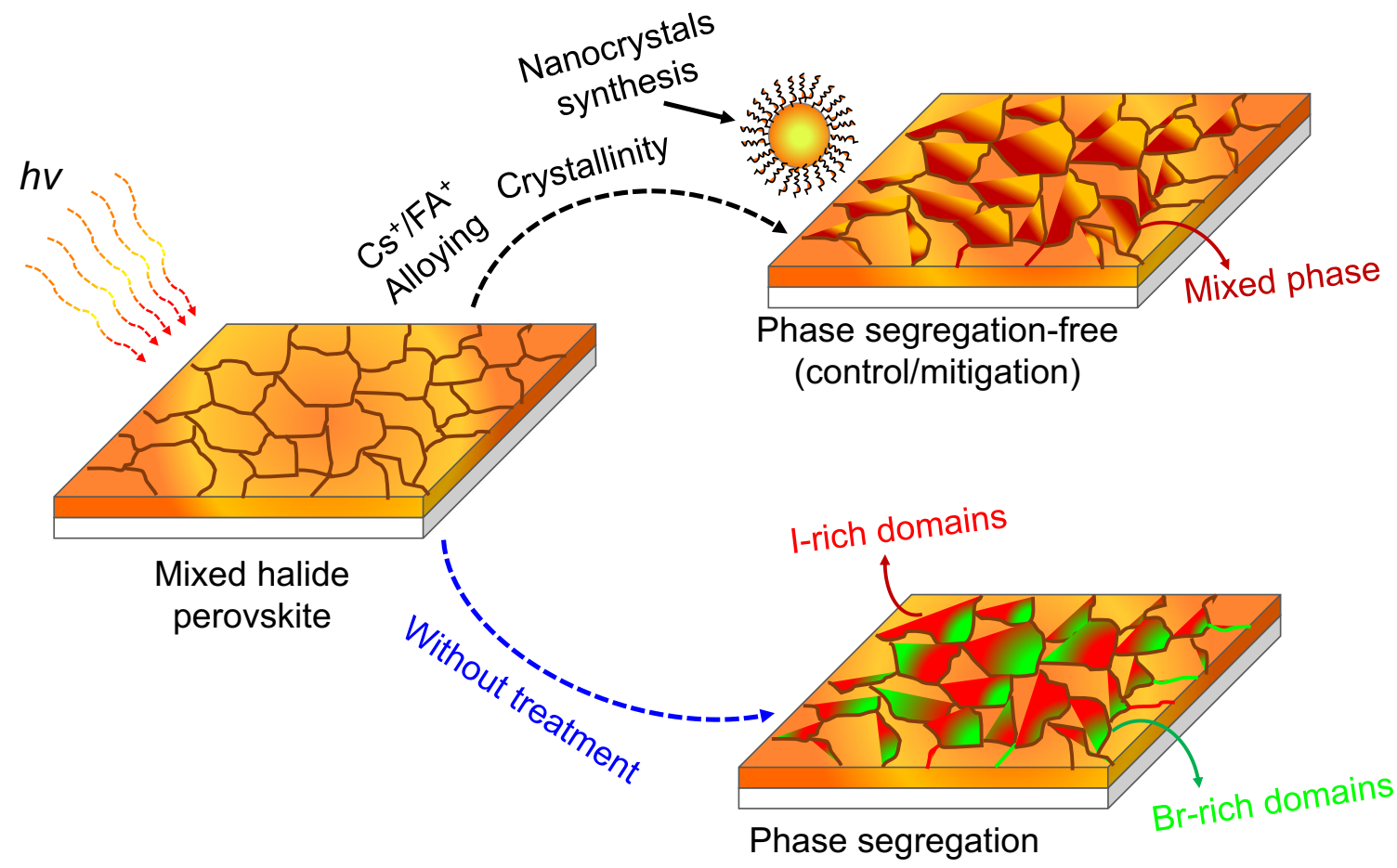




\begin{abstract}
The incorporation of halide perovskites in optoelectronics have provided a fast advance in the fabrication of new sensitizers with a balanced light-harvesting, free carrier transportation, and a progressive overcoming of the low tolerance to the moisture. Within these emerging materials, mixed halide perovskites as $\mathrm{APbX}_{3-\mathrm{x}} \mathrm{Y}_{\mathrm{x}},\left(\mathrm{A}=\mathrm{MA}^{+}, \mathrm{Cs}^{+}, \mathrm{FA}^{+} ; \mathrm{X}, \mathrm{Y}=\mathrm{Cl}^{-}, \mathrm{Br}^{-}, \mathrm{I}^{-}\right)$have been highlighted due to their facile band gap tunability in the entire visible region by varying the halide composition, which making these systems enormously appealing for the design of optoelectronic devices. Nonetheless, their performance in real devices is strongly limited as mixed halide perovskites exhibit photoinduced and current-induced phase segregation, losing their original photophysical properties and effective band gap tunability to generate halide-rich domains. The phase segregation has been the key factor to decrease the photovoltaic parameters in solar cells as open-circuit voltage and photoconversion efficiency, also limiting the performance of tandem devices and the potentiality of color design in perovskite LEDs. This review summarizes recent trends to hinder the phase segregation.
\end{abstract}

\title{
Key words
}

perovskite, mixed halide perovskite, phase segregation, solar cells,

\section{Introduction}

Since their first application in solar devices in 2003, the halide perovskites with an $\mathrm{ABX}_{3}$-type structure $\left(\mathrm{A}=\mathrm{MA}^{+}, \mathrm{Cs}^{+}, \mathrm{FA}^{+}\right.$, where $\mathrm{MA}^{+}=\mathrm{CH}_{3} \mathrm{NH}_{3}{ }^{+}, \mathrm{FA}^{+}=\mathrm{CH}\left(\mathrm{NH}_{2}\right)_{2}{ }^{+}, \mathrm{B}=\mathrm{Pb}^{2+} ; \mathrm{X}=\mathrm{Cl}^{-}, \mathrm{Br}^{-}$and $\left.\mathrm{I}^{-}\right)$have been widely studied worldwide due to outstanding characteristics as high ambipolar carrier transport and extraction capabilities, high absorption cross-section, and photoluminescence features.[1-6] The promising property of the perovskite has been successfully demonstrated in solar cell with photoconversion efficiency (PCE) over $23 \%$ in few years. [7] One approach to control the band-gap of a perovskite is by varying its halide composition, achieving a spectral response range between $\sim 1.6-2.3 \mathrm{eV}$ just by varying the ratio between I and $\mathrm{Br}$ in a mixed halide composition.[8-11] The halide interchange has been proposed to tune the perovskite band gap mixed halide perovskites with the aim to improve photovoltaic parameters in solar cells, mainly the open-circuit voltage $\left(\mathrm{V}_{\mathrm{oc}}\right)$ and incident photon to charge carrier efficiency (IPCE), $[10,12,13]$ to optimize the band gap in tandem devices,[14, 15] or to tune the photoluminescence (PL) emission.[8] However, under continuous illumination[16, 17] or applied bias,[14, 18] mixed halide perovskites undergo phase segregation, creating Br-rich and I-rich domains, as it has been first reported by Hoke et al. [16] This 
segregation leads to the losing of initial optical/electrical properties of mixed phase, favoring the formation of two high- and low-band gap states.[12, 19, 20] It has been reported that the segregated I-rich domain acts as primary free carrier recombination centers in the mixed halide perovskite, blocking electron flow into a solar device and limiting consequently the performance,[21,22] and red shifting the PL emission limiting the color design in LEDs.[14, 18] This segregated phase behaves as effective charge trap site, producing an increase of recombination and therefore a drop in the $\mathrm{V}_{\mathrm{oc}}$, being more evident this decrease as increases the bromine content in mixed $\mathrm{Br} / \mathrm{I}$ perovskites, that is the mix of halides most studied. $[12,17,19]$ in this sense, minimization of halide segregation in mixed halide perovskites is mandatory to optimize the performance of the optoelectronic devices produced with these materials.

To reduce halide segregation some works have established diverse points of view from the composition,[23-27] crystallinity,[28-30] and chemical passivation[31, 32] of mixed halide perovskites. However, a strategy to prepare phase segregation-free perovskites has not been widely discussed, likely as the possible reasons for occurring the segregation effect are not completely understood. In this review, we highlight recent alternatives to decrease the phase segregation into mixed halide perovskites as the starting point to propose novel strategies for achieving phase stability.

\section{Background about phase segregation: monitoring, dependence and influence on optoelectronics}



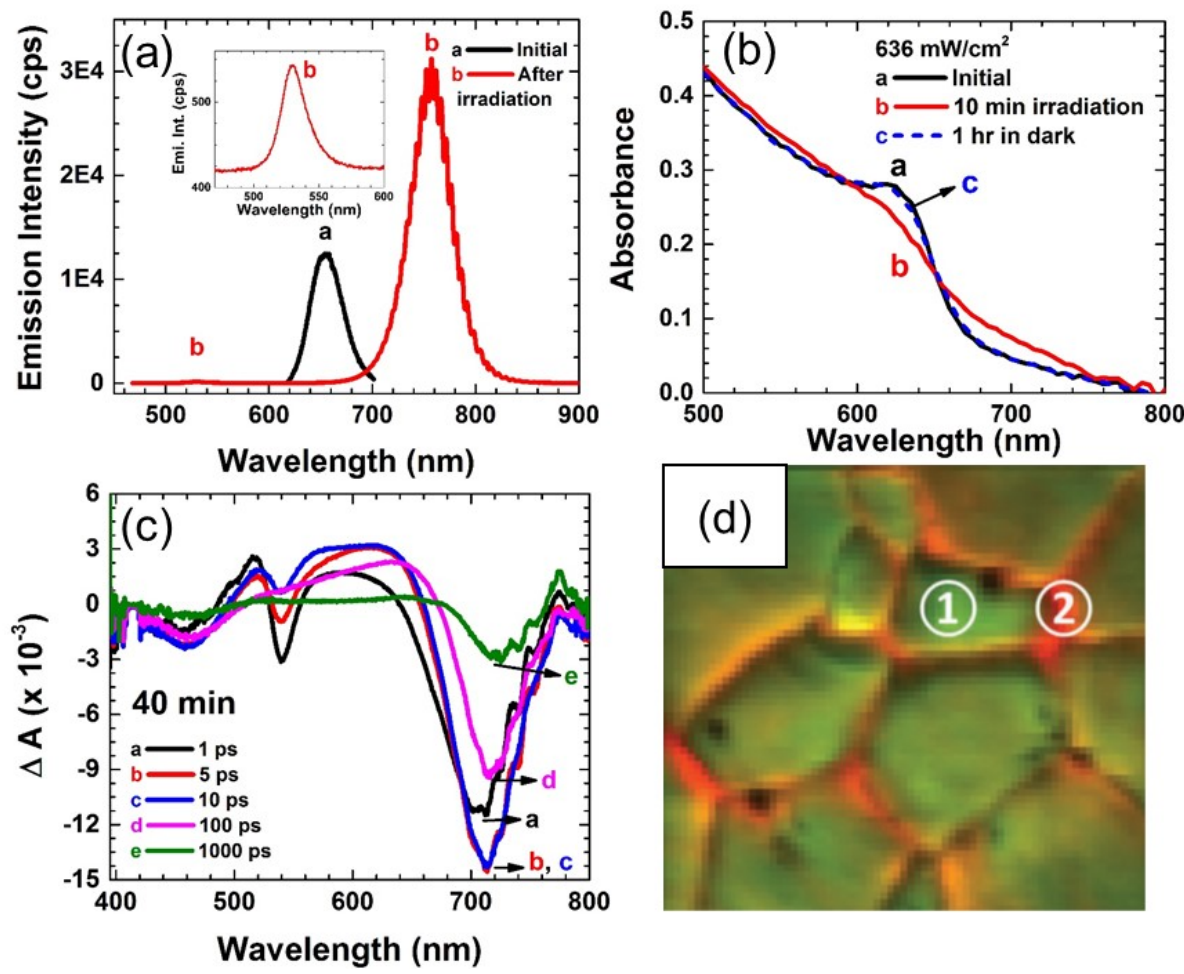

Figure 1. (a) Emission spectra and (b) absorption spectra of $\mathrm{CH}_{3} \mathrm{NH}_{3} \mathrm{PbBr}_{1.3} \mathrm{I}_{1.7}$ film before and after laser irradiation (a: $1 \mathrm{~min}$, b: $10 \mathrm{~min}$ ). (c) Time-resolved difference absorption spectra of $\mathrm{CH}_{3} \mathrm{NH}_{3} \mathrm{PbBr}_{1.3} \mathrm{I}_{1.7}$ film recorded following $387 \mathrm{~nm}$ laser pulse (pump) excitation after subjecting the sample to 40 min laser irradiation. (a-c, reprinted with permission from reference.[22] Copyright 2016 American Chemical Society) (d) SEM image of $\mathrm{CsPbBr}_{2} \mathrm{I}$ film with overlapped catholuminescence spectra (Reproduced from reference[33] with permission from The Royal Society of Chemistry). The color code in (d) indicates the emitted light wavelength in which orange regions suggest a longer emitted light wavelength than green regions.

McGehee and coworkers demonstrated reversible PL and structural change under illumination.[16] Through monitoring XRD patterns under the illumination, about $20 \%$ of two segregated domains with $20 \%$ and $70 \%$ of bromide component were found and their estimated size is around $33 \mathrm{~nm}$ and $51 \mathrm{~nm}$, respectively. Kamat and coworkers presented that the phase segregation can be tracked through absorption and transient absorption spectroscopic technique, see Figure 1ac.[22] By monitoring the spectral change over time under a suitable continuous wave laser (Figure 1a,b), the initial emission/absorption peaks of the mixed phase is decreased, while two new different signals appear, increasing their intensity with rate constant of $0.3 \mathrm{~s}^{-1} \cdot[21,22]$ It has been described that the presence of both the low-energy and high-energy peaks correspond to the segregated Br-rich 
and I-rich domains and charge transfer rate between them is about $\sim 3 \times 10^{11} \mathrm{~s}^{-1}$ (Figure 1c).[22] Also, after the photoirradiation, the spectral features from segregated domains are bleached, returning the original peak of the mixed phase. This recovery process take longer than initial segregation process, in tens of minutes to hour.

To understand the fundamental mechanism of phase segregation, various efforts have been applied. Through theoretical calculation, Brivio et al., proposed the phase diagram with dependent of $\mathrm{Br} / \mathrm{I}$ components under different temperature.[20] Thermodynamically, $\mathrm{MAPbX}_{3}$ preferred to have the segregated domain if $\mathrm{Br}$ content in the perovskite is in between $15 \%$ and $75 \%$, referred as "miscibility gap". Without photoirradiation and after 2 weeks, emission shift of $\mathrm{MAPbBr}_{1.2} \mathrm{I}_{1.8}$ from $625 \mathrm{~nm}$ to $740 \mathrm{~nm}$ supports this thermodynamically preferred segregation, presented by Friend and coworkers.[34] However, the phase segregation is quite fast and reversible phenomena compared to gradual segregation under dark after 2 weeks. It is necessary to consider role of free carriers in the perovskite matrix. Furthermore, Hillhouse and coworkers reported injected free carriers through both photoirradiation and applied bias induced the phase segregation.[14] The generated free carriers interact ions in the perovskite matrix and induce lattice strain through electron-phonon coupling, referred as polarons.[35] To reduce the lattice strain, phase segregation occurred by forming cubic Br-rich phase and orthorhombic I-rich domain.[35] Furthermore, the segregated domains are stabilized by the accumulation of polaron and the domains grow up to $30 \sim 55 \mathrm{~nm}$.[16, 21, 35] To track the location of the segregated domains, by combining morphological and spectral characterization, the segregated domain locates at grain boundary to release the lattice strain, see Figure 1d.[33] To occur phase segregation at grain boundary, early literatures calculated activation energy for ion migration and importance of defect, especially iodide movement through ion vacancies is the key to form segregated domains.[35-37] Note that activation of halide ion migration through the ion vacancy has lowest values than other A or B site cations in the perovskite.[37] Therefore, here are key points to control the phase segregation as follows: thermodynamics, grain boundary where the phase segregation occurs, defect density, and electron-phonon coupling. 
(a)
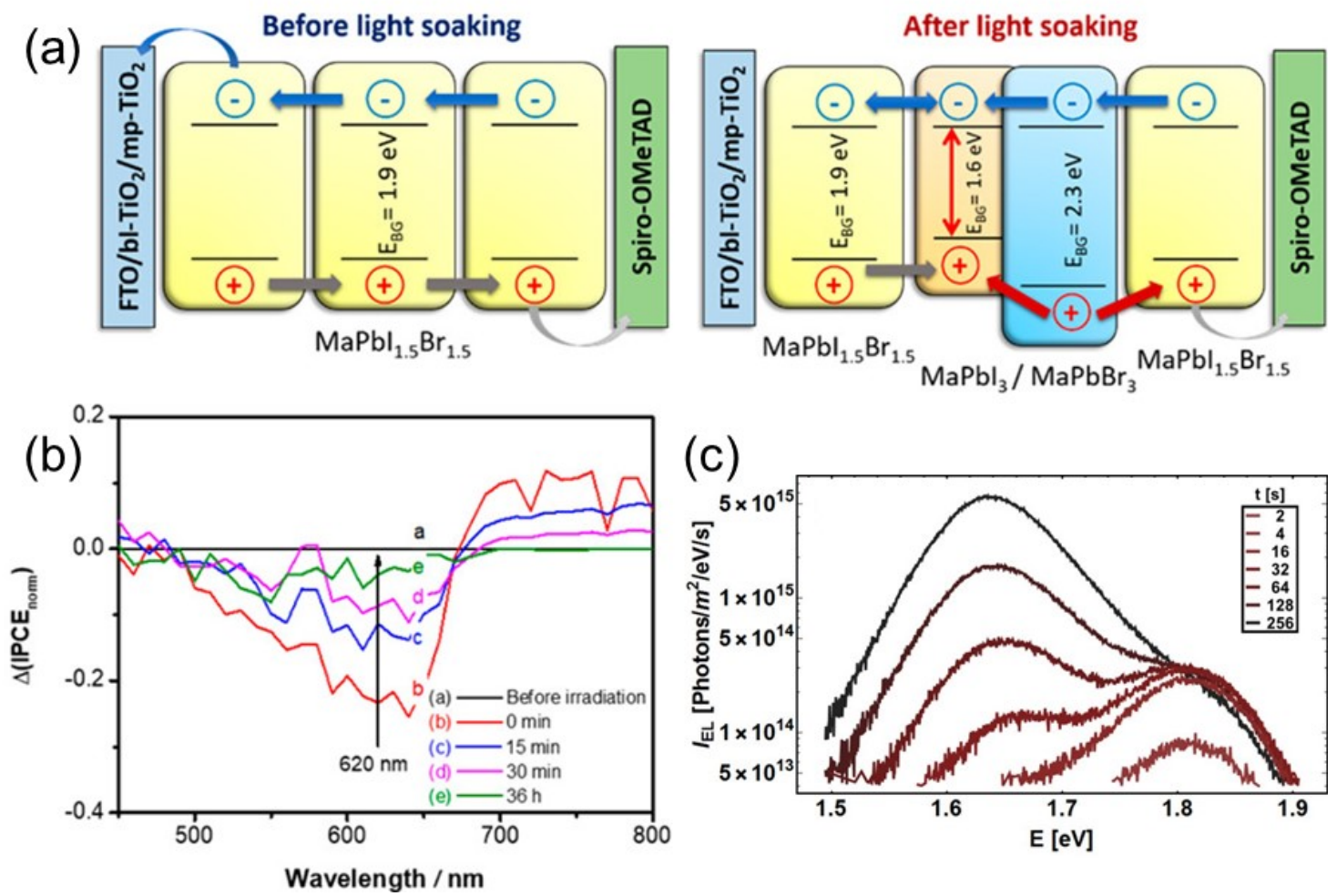

Figure 2. Effect of phase segregation to performance of solar cell (a,b) or LED (c) (Reprinted from reference.[12] Copyright 2017 American Chemical Society). (a) Schematic diagram of $\mathrm{MAPbI}_{1.5} \mathrm{Br}_{1.5}$ before/after illumination in solar cell device and charge flow process (b) Difference IPCE spectra showing the recovery of the solar cell response in the 600-700 nm region. (c) Electroluminescence spectra at selected times of a $\mathrm{MAPbBr}_{1.2} \mathrm{I}_{1.8}$ device being injected with a constant current density of $19.2 \mathrm{~mA} / \mathrm{cm}^{2}$ for $5 \mathrm{~min}$ (Reprinted with permission from reference.[14] Copyright 2017 American Chemical Society).

From the practical point of view, phase segregation produces a negative effect on the performance of optoelectronic devices, as it is summarized in Figure 2. In Figure 2a, the photogenerated electron/hole pairs in the Br-rich or mixed phase can be transferred to the low-band gap I-rich domains after light soaking.[12] The trapping of free carriers to I-rich domain is the main factor to decrease the performance of solar cells, where the carrier transport is blocked, decreasing the phovoltaic parameters as $\mathrm{V}_{\text {oc }}$, IPCE (Figure 2b) and the photoconversion efficiency (PCE) of device.[12] In the case of LEDs, the applied potential can promote the phase segregation due to charge injection and generated free carrier in the perovskite, see Figure 2c, changing the color of the emission.[14] 


\section{Strategies to control phase segregation in mixed halide perovskites}
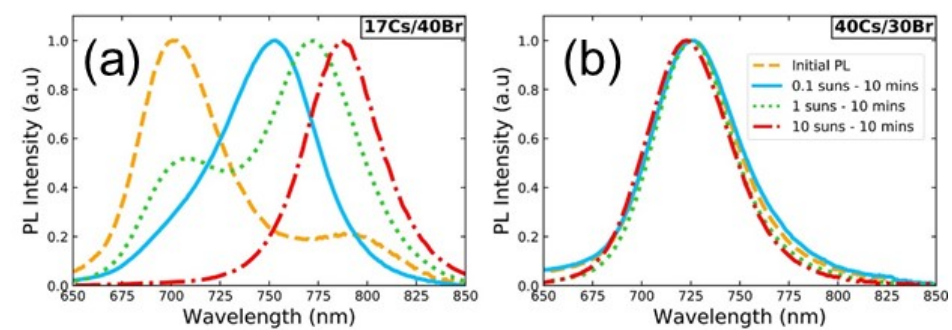

(c)
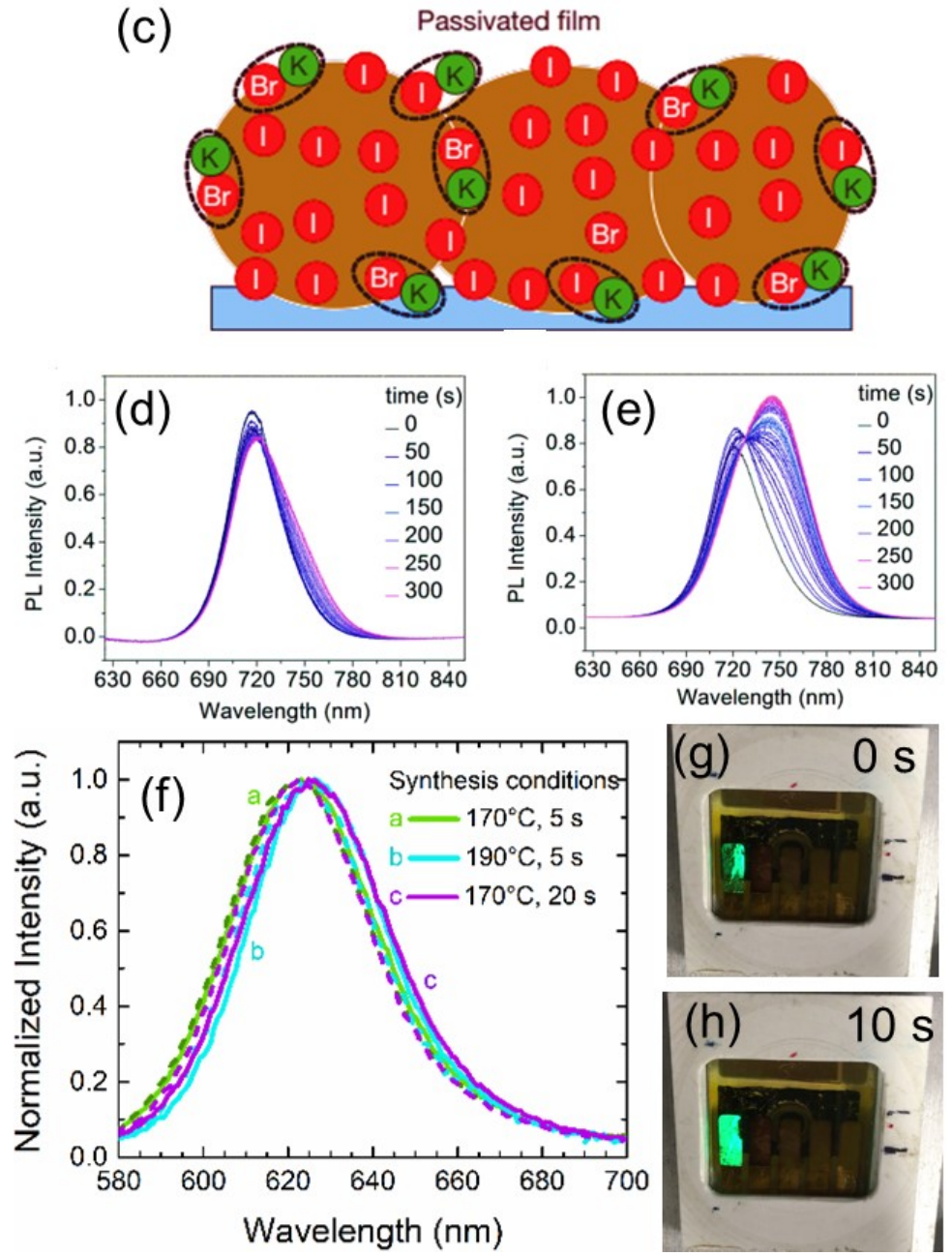

Figure 3. (a,b) PL from mixed cation and halide perovskite in device comparing (a) $\mathrm{Cs}_{0.17} \mathrm{FA}_{0.87} \mathrm{PbBr}_{1.2} \mathrm{I}_{1.8}(\mathrm{Cs} 17 / \mathrm{Br} 40)$ and (b) $\mathrm{Cs}_{0.40} \mathrm{FA}_{0.60} \mathrm{PbBr}_{0.9} \mathrm{I}_{2.1}(\mathrm{Cs} 40 / \mathrm{Br} 30)$ perovskites with a roughly $1.75 \mathrm{eV}$ band gap. The initial PL peak is shown as the orange dashed curve. The final PL peaks after $0.1,1$, and 10 suns of excitation for $10 \mathrm{~min}$ with a $488 \mathrm{~nm}$ laser are shown for each composition. Devices were held at open circuit during the measurement. (Reprinted with permission from reference.[24] Copyright 2018 American Chemical Society) (c) Schematic of a cross-section of a film showing halide-vacancy management in cases of excess halide, in which the surplus halide is 
immobilized through complexing with potassium into benign compounds at the grain boundaries and surfaces (Reprinted with permission from reference.[31] Copyright 2018 Springer Nature). (d,e) PL spectra under illumination with an interval of $10 \mathrm{sec}$ for $\mathrm{MAPbBr}_{0.8} \mathrm{I}_{2.2}$ film (d) grown on PTAA with larger grain size and (e) grown on PEDOT:PSS with smaller grain size (Reproduced from reference[28] from The Royal Society of Chemistry). (f) PL spectra of $\mathrm{CsPbBr}_{3-\mathrm{x}} \mathrm{I}_{\mathrm{x}} \mathrm{NPs}$ films (x = 1.5) before (solid line) and after (dash line) $40 \mathrm{~s}$ under $532 \mathrm{~nm} \mathrm{CW}$ laser excitation $\left(\mathrm{I}_{\mathrm{exc}}=500 \mathrm{mWcm}^{-}\right.$ ${ }^{2}$ ), varying the synthesis conditions of colloidal solutions (g,h) Green-light emission while electroluminescence measurement for $\mathrm{TiO}_{2} / \mathrm{CsPbBr}_{2.37} \mathrm{I}_{\mathrm{x} 0.63} \mathrm{NPs} /$ spiro-OMeTAD based LED device under $9 \mathrm{~V}(\mathrm{~g})$ before and $(\mathrm{h})$ after $10 \mathrm{~s}$.

Different strategies have been applied to reduce phase segregation in mixed halide perovskites. We summarize the most representing ones in this section:

i) One of the alternatives to mitigate phase segregation has been the partial replacing of cations. Conventional $\mathrm{MA}^{+}$can be replaced partially by $\mathrm{Cs}^{+}, \mathrm{FA}^{+}$, or combination of these cations (Figure 3a,b).[23-27, 38-40] The incorporation of the later cations affects the lattice strain and the grain size of the material. The mixed cation perovskites as $\mathrm{Cs}_{1-\mathrm{y}} \mathrm{MA}_{\mathrm{y}} \mathrm{PbBr}_{3-\mathrm{x}} \mathrm{I}_{\mathrm{x}}$ or $\mathrm{FA}_{1-\mathrm{y}} \mathrm{Cs}_{\mathrm{y}} \mathrm{Br}_{3-\mathrm{x}} \mathrm{I}_{\mathrm{x}}$ exhibit smaller grain sizes than conventional $\mathrm{MAPbBr}_{3-\mathrm{x}} \mathrm{I}_{\mathrm{x}}$ or $\mathrm{CsPbBr}_{3-\mathrm{x}} \mathrm{I}_{\mathrm{x}}$. Increasing the $\mathrm{Cs}^{+}(\mathrm{y}=$ 0.4)[27] or FA content $(y=0.60)$ [23] makes thermodynamically unfavorable the I-rich and Br-rich redistribution and consequently avoids phase segregation, (Figure 3a,b). Similarly, the replacing of B-cation into perovskite has been also studied. Yang et al., investigated the interchange of $\mathrm{Pb}^{2+}$ by smaller $\mathrm{Sn}^{2+}$ cations into $\mathrm{MASn}_{1-\mathrm{y}} \mathrm{Pb}_{\mathrm{y}} \mathrm{Br}_{3-\mathrm{x}} \mathrm{I}_{\mathrm{x}}(\mathrm{y}=0.25)$, deducing by PL and XRD measurements that $\mathrm{Sn}^{2+}$ increase the microstrain in the perovskite lattice and acts as a barrier for the halide migration.[38] Both approaches suggest the decrease of the trap-assisted non-radiative recombination induced by GB. Even so, most of mixed cation-mixed halide perovskites are free from the phase segregation but still it is possible find some mixed cation-mixed halide perovskites in which phase segregation is observed, see Figure $3 \mathrm{a}$ where halide perovskite with mixing portion (17\% Cs $83 \% \mathrm{FA})$ shows phase segregation.

ii) To avoid the formation of halide-rich clusters in grain boundary of mixed cation/halide perovskites, the potassium passivation has been performed.[31] Stranks and coworkers synthetized a triple-cation ( $\mathrm{Cs}, \mathrm{FA}, \mathrm{MA}) \mathrm{PbBr}_{3-\mathrm{x}} \mathrm{I}_{\mathrm{x}}$, dissolving certain amount of potassium iodide (KI) into the perovskite precursor solution.[31] They proposed that iodide ions from KI can fill the halide vacancies, while the $\mathrm{K}^{+}$cations act as a "halide-sequesters" near to the grain boundary into the perovskite (Figure 3c). In this way, halide migration can be suppressed, enhancing the PCE of perovskite-based solar cells. An alternative passivation approach considers the use of organic ligands 
to fill the trap states, defects or react with halides under diffusion process into the perovskite.[32] Organic as choline chloride or PCBM acts as Lewis acids favoring the halide coordination, which can also retard the halide migration to the trap states as grain boundary.

iii) Another interesting alternative to control halide segregation comes from a morphological point of view. As reported by Huang and coworkers, improved crystallinity of the $\mathrm{MAPbBr}_{3-\mathrm{x}} \mathrm{I}_{\mathrm{x}}$ film on PTAA as a hole transporter can facilitate/hinder phase segregation into material (Figure $3 \mathrm{~d}$ ). Conversely, poor crystalline perovskite film grown on PEDOT:PSS generates small grains with larger content of defects or grain boundary and so the segregation is facilitated in the poor crystalline perovskite films (Figure 3e).[28]

iv) Lastly, an efficient strategy to inhibit the halide segregation has been achieved to incorporate a new synthetic route for mixed halide perovskites by the preparation of materials with lower dimensionality. The use of long-chain ammonium ligand capped nanometer-sized crystallites, as n-butylammonium, producing $2 \mathrm{D} / 3 \mathrm{D}$ perovskite architectures can inhibit phase segregation and preserve a real LED color tunability.[18] Further reduction of dimensionality by the use of colloidal perovskite nanoparticles (NPs) can also inhibit phase segregation in mixed halide perovskites.[21] Despite, the preparation of perovskite NPs has been recently reported, these materials produces very high PLQY with simple synthesis processes.[11, 41, 42] Our group has prepared colloidal $\mathrm{CsPbBr}_{3-}$ ${ }_{x} I_{x}$ NPs by hot injection method, $[11,41]$ varying the synthesis temperature and reaction time. Finally, we have produced thin films by drop casting, using perovskite NP from colloidal solutions as building blocks. Through PL measurements of $\mathrm{CsPbBr}_{1.5} \mathrm{I}_{1.5} \mathrm{NP}$ films by using a high intensity continuous waver laser $\left(532 \mathrm{~nm}, 500 \mathrm{mWcm}^{-2}\right)$, we observed that the emission peak position of materials was not shifted over the time, concluding that nanocrystals are phase-segregation free, (Figure $3 \mathrm{f}$ ). The NPs did not show agglomerations to generate interfacial electron traps or GB, inhibiting the halide migration and thereby the segregation effect. Consequently, optoelectronic devices fabricated with perovskite NPs do not suffer of phase segregation. As shown in Figure 3g,h, an unchanged emissive green-color was achieved in a $\mathrm{CsPbBr}_{3-\mathrm{x}} \mathrm{I}_{\mathrm{x}}$ QDs $(\mathrm{x}=0.75)$ based LED device under $9 \mathrm{~V}$, confirming the mitigation of segregation effect.

\section{Conclusions}

The mixed halide perovskites are, without doubts, an essential factor to improve the performance of optoelectronic devices for energy conversion and light production in coming years. However, the halide segregation under photoirradiation limits the expansion of their applicability, due to the perovskite features as composition, morphology and crystallinity. These characteristics are closely 
associated with the generation of structural defects as halide vacancies or grain boundaries, which are considered as the critical points to induce the halide migration, accumulation and thereby, the assumption of segregation effect. By a comprehensive understanding of the A-cation and B-cation alloying, passivation process of structural defects, enhancing the crystallinity and the reduction of the perovskite dimensionality, not only the halide segregation can be retarded, but also the preparation of phase segregation-free mixed halide perovskites can be achieved. In this way, the full potential of these materials can be unlocked.

\section{Declarations of interest}

The authors declare no competing financial interest.

\section{Acknowledgments}

This work was supported by the European Research Council (ERC) via Consolidator Grant (724424

- No-LIMIT). A. F. Gualdrón-Reyes acknowledges to Colciencias for a Ph.D 617-scholarship and Universidad Industrial de Santander through the Colciencias project 8836, external code 110265843664.

\section{References:}

* Paper of special interest

** Paper of outstanding interest

[1] E.M. Talbert, H.F. Zarick, A. Boulesbaa, N. Soetan, A.A. Puretzky, D.B. Geohegan, R. Bardhan, Bromine Substitution Improves Excited-Sstate Dynamics in Mesoporous Mixed Halide Perovskite Films, Nanoscale, 9 (2017) 12005-12013.

[2] M. Saliba, T. Matsui, J.Y. Seo, K. Domanski, J.P. Correa-Baena, M.K. Nazeeruddin, S.M. Zakeeruddin, W. Tress, A. Abate, A. Hagfeldt, M. Gratzel, Cesium-Containing Triple Cation Perovskite Solar Cells: Improved Stability, Reproducibility and High Efficiency, Energ Environ Sci, 9 (2016) 1989-1997.

[3] R.J. Stoddard, F.T. Eickemeyer, J.K. Katahara, H.W. Hillhouse, Correlation between Photoluminescence and Carrier Transport and a Simple In Situ Passivation Method for High-Bandgap Hybrid Perovskites, J. Phys. Chem. Lett., 8 (2017) 3289-3298.

[4] J.S. Yun, J. Seidel, J. Kim, A.M. Soufiani, S. Huang, J. Lau, N.J. Jeon, S.I. Seok, M.A. Green, A. Ho-Baillie, Critical Role of Grain Boundaries for Ion Migration in Formamidinium and Methylammonium Lead Halide Perovskite Solar Cells, Adv. Energ. Mater., 6 (2016) 1600330-n/a.

[5] S.D. Stranks, G.E. Eperon, G. Grancini, C. Menelaou, M.J.P. Alcocer, T. Leijtens, L.M. Herz, A. Petrozza, H.J. Snaith, Electron-Hole Diffusion Lengths Exceeding 1 Micrometer in an Organometal Trihalide Perovskite Absorber, Science, 342 (2013) 341-344.

[6] G. Giorgi, J.I. Fujisawa, H. Segawa, K. Yamashita, Small Photocarrier Effective Masses Featuring Ambipolar Transport in Methylammonium Lead Iodide Perovskite: A Density Functional Analysis, J. Phys. Chem. Lett., 4 (2013) 4213-4216. 
[7] Research Cell Record Efficiency Chart, National Renewable Energy Laboratory (NREL), 2017. [8] L. Gil-Escrig, A. Miquel-Sempere, M. Sessolo, H.J. Bolink, Mixed Iodide-Bromide Methylammonium Lead Perovskite-based Diodes for Light Emission and Photovoltaics, J. Phys. Chem. Lett., 6 (2015) 3743-3748.

[9] I.L. Braly, H.W. Hillhouse, Optoelectronic Quality and Stability of Hybrid Perovskites from $\mathrm{MAPbI}_{3}$ to $\mathrm{MAPbI}_{2} \mathrm{Br}$ Using Composition Spread Libraries, J. Phys. Chem. C, 120 (2016) 893-902. [10] J.H. Noh, S.H. Im, J.H. Heo, T.N. Mandal, S.I. Seok, Chemical Management for Colorful, Efficient, and Stable Inorganic-Organic Hybrid Nanostructured Solar Cells, Nano Lett, 13 (2013) 1764-1769.

[11] G. Nedelcu, L. Protesescu, S. Yakunin, M.I. Bodnarchuk, M.J. Grotevent, M.V. Kovalenko, Fast Anion-Exchange in Highly Luminescent Nanocrystals of Cesium Lead Halide Perovskites $\left(\mathrm{CsPbX}_{3}\right.$, $\mathrm{X}=\mathrm{Cl}, \mathrm{Br}, \mathrm{I})$, Nano Lett, 15 (2015) 5635-5640.

* [12] G.F. Samu, C. Janáky, P.V. Kamat, A Victim of Halide Ion Segregation. How Light Soaking Affects Solar Cell Performance of Mixed Halide Lead Perovskites, ACS Energy Lett., 2 (2017) 18601861.

This paper demonstrated effect of phase segregation for photovoltaic performance and long term stability with reversible IPCE results. In presence of segregated I-rich domain, the generated current traps into the I-rich domain so overall performance is suppressed.

[13] T.J. Jacobsson, J.P. Correa-Baen, M. Pazoki, M. Saliba, K. Schenk, M. Gratzel, A. Hagfeldt, Exploration of the Compositional Space for Mixed Lead Halogen Perovskites for High Efficiency Solar Cells, Energ Environ Sci, 9 (2016) 1706-1724.

*[14] I.L. Braly, R.J. Stoddard, A. Rajagopal, A.R. Uhl, J.K. Katahara, A.K.Y. Jen, H.W. Hillhouse, Current-Induced Phase Segregation in Mixed Halide Hybrid Perovskites and its Impact on TwoTerminal Tandem Solar Cell Design, ACS Energy Lett., 2 (2017) 1841-1847.

This manuscript shows that phase segregation in mixed halide perovskites is not just a photoinduced effect but current induced effect, afecting consecuentely the performance of the LEDs prepared with these materials.

[15] T.C.-J. Yang, P. Fiala, Q. Jeangros, C. Ballif, High-Bandgap Perovskite Materials for Multijunction Solar Cells, Joule, (2018).

**[16] E.T. Hoke, D.J. Slotcavage, E.R. Dohner, A.R. Bowring, H.I. Karunadasa, M.D. McGehee, Reversible Photo-Induced Trap Formation in Mixed-halide Hybrid Perovskites for Photovoltaics, Chem Sci, 6 (2015) 613-617.

This is the first paper reporting the phase segregation effect under illumination in mixed halide perovskites. A broad range of of $\mathrm{Br} / \mathrm{I}$ ratios was explored and careful analyzed. Due to the inportance of this seminal work in some paper this effect is call "Hoke Effect".

*[17] E.L. Unger, L. Kegelmann, K. Suchan, D. Sorell, L. Korte, S. Albrecht, Roadmap and Roadblocks for the Band Gap Tunability of Metal Halide perovskites, J. Mater. Chem. A, 5 (2017) 11401-11409.

This is a review paper collectioins a broad range of examples of phase segregation in mixed halides perovskite solar cells using different kinds of halide perovskites. The deleuterios effect on the cell performance of this effect is highlighted.

[18] J. Xu, Z. Hu, L. Huang, X. Huang, X. Jia, J. Zhang, J. Zhang, Y. Zhu, In situ recycle of $\mathrm{PbI}_{2}$ as a step towards sustainable perovskite solar cells, Prog. Photovolt: Res. Appl., 25 (2017) 1022-1033. [19] R.E. Beal, D.J. Slotcavage, T. Leijtens, A.R. Bowring, R.A. Belisle, W.H. Nguyen, G.F. Burkhard, E.T. Hoke, M.D. McGehee, Cesium Lead Halide Perovskites with Improved Stability for Tandem Solar Cells, J. Phys. Chem. Lett., 7 (2016) 746-751. 
[20] F. Brivio, C. Caetano, A. Walsh, Thermodynamic Origin of Photoinstability in the $\mathrm{CH}_{3} \mathrm{NH}_{3} \mathrm{~Pb}\left(\mathrm{I}_{1}\right.$ $\left.{ }_{x} \mathrm{Br}_{\mathrm{x}}\right)_{3}$ Hybrid Halide Perovskite Alloy, J. Phys. Chem. Lett., 7 (2016) 1083-1087.

* [21] S. Draguta, O. Sharia, S.J. Yoon, M.C. Brennan, Y.V. Morozov, J.S. Manser, P.V. Kamat, W.F. Schneider, M. Kuno, Rationalizing the Light-induced Phase Separation of Mixed Halide Organic-inorganic Perovskites, Nature communications, 8 (2017) 200.

The authors presented detailed mechanism of phase segregation through both experimental and theorical ways. By developing the model for phase segregation, they provided various factors to affect rate of segregation and recovery. Furthermore, with dependance on diffusion length and excitation power density, the authors provided phase diagram and demonstrated stable region against to phase segregation by forming few nanometer sized dot shape.

* [22] S.J. Yoon, S. Draguta, J.S. Manser, O. Sharia, W.F. Schneider, M. Kuno, P.V. Kamat, Tracking Iodide and Bromide Ion Segregation in Mixed Halide Lead Perovskites during Photoirradiation, ACS Energy Lett., 1 (2016) 290-296.

The paper tracked the two segregated domains (Br-rich and I-rich domains) as function of irradiation time through various photophysical characterizations: absorption, emission, and transient absorption. They provided quantative rate of phase segregation and recovery. The paper also shows how charge transfers from segregated Br-rich domain to I-rich domain in few picoseconds.

**[23] D.P. McMeekin, G. Sadoughi, W. Rehman, G.E. Eperon, M. Saliba, M.T. Horantner, A. Haghighirad, N. Sakai, L. Korte, B. Rech, M.B. Johnston, L.M. Herz, H.J. Snaith, A Mixed-Cation Lead Mixed-Halide Perovskite Absorber for Tandem Solar Cells, Science, 351 (2016) 151-155.

The authors firstly provided the strategy to avoid the phase segregation by mixing various A-site cations. Furthermore, applying the mixed cation and halide perovskitehe perovskite to tandem cells with silicon solar cell, they demonstrated the feasiblity of the perovskite in the tandem cell configuration.

* [24] K.A. Bush, K. Frohna, R. Prasanna, R.E. Beal, T. Leijtens, S.A. Swifter, M.D. McGehee, Compositional Engineering for Efficient Wide Band Gap Perovskites with Improved Stability to Photoinduced Phase Segregation, ACS Energy Lett., 3 (2018) 428-435.

By varying A site cations and $\mathrm{X}$ site halide anions, the authors find ideal composition of mixed cation and halide perovskite, free from the phase segregation. Furthermore, the optimum compositions of perovskite were demonstrated in photovoltaic devices and checked its photostabilities.

[25] G.W.P. Adhyaksa, L.W. Veldhuizen, Y. Kuang, S. Brittman, R.E.I. Schropp, E.C. Garnett, Carrier Diffusion Lengths in Hybrid Perovskites: Processing, Composition, Aging, and Surface Passivation Effects, Chem. Mater., 28 (2016) 5259-5263.

[26] P. Gratia, G. Grancini, J.-N. Audinot, X. Jeanbourquin, E. Mosconi, I. Zimmermann, D. Dowsett, Y. Lee, M. Grätzel, F. De Angelis, K. Sivula, T. Wirtz, M.K. Nazeeruddin, Intrinsic Halide Segregation at Nanometer Scale Determines the High Efficiency of Mixed Cation/Mixed Halide Perovskite Solar Cells, J. Am. Chem. Soc., 138 (2016) 15821-15824.

[27] Z. Xiao, L. Zhao, N.L. Tran, Y.L. Lin, S.H. Silver, R.A. Kerner, N. Yao, A. Kahn, G.D. Scholes, B.P. Rand, Mixed-Halide Perovskites with Stabilized Bandgaps, Nano Lett., 17 (2017) 6863-6869.

[28] M. Hu, C. Bi, Y. Yuan, Y. Bai, J. Huang, Stabilized Wide Bandgap MAPbBr $\mathrm{I}_{3-\mathrm{x}}$ Perovskite by Enhanced Grain Size and Improved Crystallinity, Advanced science, 3 (2016) 1500301.

[29] M. Ralaiarisoa, Y. Busby, J. Frisch, I. Salzmann, J.J. Pireaux, N. Koch, Correlation of Annealing Time with Crystal Structure, Composition, and Electronic Properties of $\mathrm{CH}_{3} \mathrm{NH}_{3} \mathrm{PbI}_{3-\mathrm{x}} \mathrm{Cl}_{\mathrm{x}}$ Mixedhalide Perovskite Films, Physical chemistry chemical physics : PCCP, 19 (2016) 828-836.

[30] W. Rehman, D.P. McMeekin, J.B. Patel, R.L. Milot, M.B. Johnston, H.J. Snaith, L.M. Herz, Photovoltaic Mixed-cation Lead Mixed-halide Perovskites: Links Between Crystallinity, Photostability and Electronic Properties, Energ. Environ. Sci, 10 (2017) 361-369. 
** [31] M. Abdi-Jalebi, Z. Andaji-Garmaroudi, S. Cacovich, C. Stavrakas, B. Philippe, J.M. Richter, M. Alsari, E.P. Booker, E.M. Hutter, A.J. Pearson, S. Lilliu, T.J. Savenije, H. Rensmo, G. Divitini, C. Ducati, R.H. Friend, S.D. Stranks, Maximizing and Stabilizing Lluminescence from Halide Perovskites with Potassium Passivation, Nature, 555 (2018) 497-501.

Through potassion passitvation on the surface of perovskite, the authors demonstrated different strategy to improve photostability by minimizing the phase segregation. Inhibition of surface defect as the site where the phase segregation, they presented enhanced photostability, improved device long term stabiltiy. Furthermore, since this passiviation reduces non-recombination sites, the improved photovoltaic performance was also demonstrated with increased charge collection efficiency.

[32] X. Zheng, B. Chen, J. Dai, Y. Fang, Y. Bai, Y. Lin, H. Wei, Xiao C. Zeng, J. Huang, Defect passivation in hybrid perovskite solar cells using quaternary ammonium halide anions and cations, Nature Energy, 2 (2017) 17102.

[33] W. Li, M.U. Rothmann, A. Liu, Z. Wang, Y. Zhang, A.R. Pascoe, J. Lu, L. Jiang, Y. Chen, F. Huang, Y. Peng, Q. Bao, J. Etheridge, U. Bach, Y.B. Cheng, Phase Segregation Enhanced Ion Movement in Efficient Inorganic CsPbIBr 2 Solar Cells, Adv. Energy Mater., 7 (2017) 1700946.

[34] A. Sadhanala, F. Deschler, T.H. Thomas, S.E. Dutton, K.C. Goedel, F.C. Hanusch, M.L. Lai, U. Steiner, T. Bein, P. Docampo, D. Cahen, R.H. Friend, Preparation of Single-Phase Films of $\mathrm{CH}_{3} \mathrm{NH}_{3} \mathrm{~Pb}\left(\mathrm{I}_{1-\mathrm{x}} \mathrm{Br}_{\mathrm{x}}\right)_{3}$ with Sharp Optical Band Edges, J. Phys. Chem. Lett., 5 (2014) 2501-2505.

** [35] C.G. Bischak, C.L. Hetherington, H. Wu, S. Aloni, D.F. Ogletree, D.T. Limmer, N.S. Ginsberg, Origin of Reversible Photoinduced Phase Separation in Hybrid Perovskites, Nano Lett, 17 (2017) 1028-1033.

The authors demonstrated the segregated I-rich domain at grain boundaries by tracking cathodoluminescence in SEM. Furthermore, with DFT calculation, they provide detailed thermodynamic of the process and estimate $\sim 8 \mathrm{~nm}$ size of segregation I-rich domain. They also provide how polarons cause phase segregation.

[36] A.J. Barker, A. Sadhanala, F. Deschler, M. Gandini, S.P. Senanayak, P.M. Pearce, E. Mosconi, A.J. Pearson, Y. Wu, A.R. Srimath Kandada, T. Leijtens, F. De Angelis, S.E. Dutton, A. Petrozza, R.H. Friend, Defect-Assisted Photoinduced Halide Segregation in Mixed-Halide Perovskite Thin Films, ACS Energy Lett., 2 (2017) 1416-1424.

* [37] M.C. Brennan, S. Draguta, P.V. Kamat, M. Kuno, Light-Induced Anion Phase Segregation in Mixed Halide Perovskites, ACS Energy Lett., 3 (2018) 204-213.

This paper provide comprehensive review about fundamentals of phase segregation and remained unknown issues or challenges.

[38] Z. Yang, A. Rajagopal, S.B. Jo, C.C. Chueh, S. Williams, C.C. Huang, J.K. Katahara, H.W. Hillhouse, A.K. Jen, Stabilized Wide Bandgap Perovskite Solar Cells by Tin Substitution, Nano Lett, 16 (2016) 7739-7747.

[39] D.P. McMeekin, Z. Wang, W. Rehman, F. Pulvirenti, J.B. Patel, N.K. Noel, M.B. Johnston, S.R. Marder, L.M. Herz, H.J. Snaith, Crystallization Kinetics and Morphology Control of Formamidinium-Cesium Mixed-Cation Lead Mixed-Halide Perovskite via Tunability of the Colloidal Precursor Solution, Advanced materials, 29 (2017).

[40] G.E. Eperon, T. Leijtens, K.A. Bush, R. Prasanna, T. Green, J.T. Wang, D.P. McMeekin, G. Volonakis, R.L. Milot, R. May, A. Palmstrom, D.J. Slotcavage, R.A. Belisle, J.B. Patel, E.S. Parrott, R.J. Sutton, W. Ma, F. Moghadam, B. Conings, A. Babayigit, H.G. Boyen, S. Bent, F. Giustino, L.M. Herz, M.B. Johnston, M.D. McGehee, H.J. Snaith, Perovskite-perovskite Tandem Photovoltaics with Optimized Band Gaps, Science, 354 (2016) 861-865.

[41] L. Protesescu, S. Yakunin, M.I. Bodnarchuk, F. Krieg, R. Caputo, C.H. Hendon, R.X. Yang, A. Walsh, M.V. Kovalenko, Nanocrystals of Cesium Lead Halide Perovskites $\left(\mathrm{CsPbX}_{3}, \mathrm{X}=\mathrm{Cl}, \mathrm{Br}\right.$, and 
I): Novel Optoelectronic Materials Showing Bright Emission with Wide Color Gamut, Nano Lett, 15 (2015) 3692-3696.

[42] L.C. Schmidt, A. Pertegás, S. González-Carrero, O. Malinkiewicz, S. Agouram, G. Mínguez Espallargas, H.J. Bolink, R.E. Galian, J. Pérez-Prieto, Nontemplate Synthesis of $\mathrm{CH}_{3} \mathrm{NH}_{3} \mathrm{PbBr}_{3}$ Perovskite Nanoparticles, J. Am. Chem. Soc., 136 (2014) 850-853. 